\title{
Ô nhiễm rác thải sinh hoạt nông thôn Việt Nam: Nguyên nhân do đâu?
}

\author{
Đỗ Thùy Trang, Ngô Thị Ngọc Bích \\ Đại học Quốc gia Hà Nội
}

Hà Nội, ngày 27 tháng 12 năm 2021

\section{Preprint DOI: 10.31219/osf.io/86z9t}

Rác thải sinh hoạt từ lâu đã được coi là một trong những vấn đề môi trường cấp bách cần được nhanh chóng tìm hướng giải quyết tại Việt Nam. Ta không chỉ chứng kiến sự quá tải và ô nhiễm về rác thải sinh hoạt tại những khu đô thị phát triển, mà thực tế, nó còn đang dần dần hủy hoại hệ sinh thái trong sạch của khu vực nông thôn Việt Nam. Vậy nguyên nhân nào dẫn đến sự quá tải và ô nhiễm rác thải sinh hoạt nông thôn Việt Nam?

Dựa trên tình hình thực tế và thông qua một vài đề tài nghiên cứu, nguyên nhân dẫn đến sự ô nhiễm rác thải sinh hoạt tại nông thôn chủ yếu bắt nguồn từ bốn lý do sau: hoạt động sản xuất, kinh doanh của hộ gia đình; lối sống của người dân; hoạt động xả thải của các nhà máy, khu công nghiệp và hệ thống quản lý, xử lý rác thải sinh hoạt.

Nguyên nhân đầu tiên đến từ hoạt động sản xuất, kinh doanh của hộ gia đình. Trên thực tế, tại hầu hết nông thôn Việt Nam, đặc biệt là tại những vùng nông thôn nơi có các làng nghề truyền thống, điều này đã khiến cho lượng rác thải từ hoạt động sản xuất ngày càng tăng lên.

Nguyên nhân thứ hai đó là văn hóa. Văn hóa môi trường gồm có nhận thức, lối sống, hành vi trong việc bảo vệ tài nguyên, môi trường (rác) chưa thực sự thấm vào đời sống người dân (Nguyen \& Vuong, 2021; Q.-H. Vuong, 2021; Q. H. Vuong, 2021; Q. H. Vuong et al., 2021). Người dân vẫn có thói quen xả rác bừa bãi, ý thức bảo vệ môi trường chưa cao, ít có hành động cụ thể để làm giảm ô nhiễm môi trường (rác). Đây được coi là vấn đề cốt lõi đòi hỏi phải giải quyết triệt để trong vấn đề bảo vệ môi trường. Có thể dễ dàng nhận thấy rằng, nhận thức của người dân tại nông thôn về rác thải sinh hoạt còn vô cùng yếu kém. Thứ nhất, ta có thể thấy rằng phần lớn người dân thường không phân loại các loại rác thải như rác hữu cơ, rác tái chế, rác có hại.. thành những thùng rác riêng. Điều này khiến cho tất cả các loại rác đều được để chung một túi, một bao, tạo thành sự 
hỗn độn khó chịu. Thứ hai, vẫn có những người dân với tâm lý thờ ơ, "tiện tay" vứt rác, thấy chỗ nào hợp để quăng rác thì có thể quăng luôn. Chính việc vứt rác không đúng nơi quy định như này đã khiến cho khắp nơi đâu đâu cũng thấy rác. Thứ ba, hầu hết người dân tại nông thôn đều e ngại trong việc đóng tiền cho việc thu gom, xử lý rác thải tại địa phương. Chỉ $50.000 \mathrm{VNĐ} \mathrm{một} \mathrm{tháng} \mathrm{cho} \mathrm{tất} \mathrm{cả} \mathrm{hoạt}$ động đó, thế nhưng có mấy ai cảm thấy hoàn toàn tự nguyện chi trả cho khoản tiền đó.

Hệ thống quản lý và xử lý rác thải sinh hoạt còn yếu kém cũng là một trong những nguyên nhân gây ra ô nhiễm môi trường ở khu vực nông thôn. Thực tế, trên cả nước đã có khoảng $50 \%$ các xã thành lập tổ thu gom chất thải sinh hoạt(Hòa, 2020). Tuy nhiên, công ty dịch vụ môi trường chỉ vận chuyển một số ít chất thải rắn sinh hoạt, còn phần lớn là do các hợp tác xã, tổ, đội tự quản với chi phí thu gom thỏa thuận. Với số tiền $50.000 \mathrm{VNĐ/hộ/tháng} \mathrm{như} \mathrm{trên} \mathrm{thì} \mathrm{chi} \mathrm{phí}$ này hoàn toàn không đủ để chi trả cho cả hoạt động duy trì hay vận chuyển rác thải. Bên cạnh đó còn tồn tại những bất cập trong việc quy hoạch các địa điểm xử lý rác dẫn đến xã nào cũng có một lò đốt chất thải hay những bãi chôn lấp chất thải không đảm bảo yêu cầu kỹ thuật. Từ đó có thể thấy rằng, quản lý và xử lý rác thải sinh hoạt không tốt còn dẫn đến ô nhiễm môi trường đất, môi trường không khí.

Nguyên nhân cuối cùng đến từ việc gia tăng các khu công nghiệp tại khu vực nông thôn. Theo quá trình Công nghiệp hóa - Hiện đại hóa và xây dựng nông thôn mới, số lượng các nhà máy, xí nghiệp ở vùng nông thôn tăng lên nhanh chóng. Bên cạnh việc tăng trưởng, phát triển kinh tế khu vực thì các khu công nghiệp cũng đã gây ra hậu quả nghiêm trọng đối với môi trường sống tại khu vực qua hoạt động xả thải không qua xử lý. Đây cũng là thiếu sót lớn trong công tác giám sát, quản lý rác thải trong khu công nghiệp ở vùng nông thôn.

Nhìn chung, ô nhiễm môi trường sống ở khu vực nông thôn không tự nhiên mà có. Nó là một quá trình tích lũy theo thời gian, là kết quả của sự thiếu ý thức của mỗi người dân. Và, giải quyết vấn đề ô nhiễm môi trường cần một khoảng thời gian không hề ngắn cùng sự phối hợp giữa chính quyền địa phương với người dân khu vực. Gốc rễ vấn đề có thể nằm ở văn hóa môi trường. Trong thời gian tới việc giáo dục nhận thức cho công dân, đặc biệt là cho thế hệ trẻ về môi trường, sử dụng tiết kiệm tài nguyên, bảo vệ môi trường, thúc đẩy các sáng kiến để xử lý ô nhiễm môi trường (rác) là cần ưu tiên và thực hiện (Q. Vuong, 2020). 


\section{TÀI LIỆU THAM KHẢO}

Hòa, T. (2020). Rác thải nông thôn- Thực trạng và định hướng quản lý. Con Số Sự Kiện. http://consosukien.vn/rac-tha-i-nong-thon-thu-c-tra-ng-va-di-nhhuong-qua-n-ly.htm

Nguyen, M.-H., \& Vuong, Q.-H. (2021). Evaluation of the Aichi Biodiversity Targets: the international collaboration trilemma in interdisciplinary research. Pacific Conservation Biology. https://doi.org/10.1071/pc21026

Vuong, Q.-H. (2021). Western monopoly of climate science is creating an ecodeficit culture. Economy, Land \& Climate Insight, 1-9.

Vuong, Q. (2020). From children's literature to sustainability science, and young scientists for a more sustainable Earth. Journal of Sustainability Education, 24(December).

Vuong, Q. H. (2021). The semiconducting principle of monetary and environmental values exchange. Economics and Business Letters, 10(3), 284-290. https://doi.org/10.17811/ebl.10.3.2021.284-290

Vuong, Q. H., Ho, M. T., Nguyen, M. H., Pham, T. H., Vuong, T. T., Khuc, Q., Ho, H. A., \& La, V. P. (2021). On the environment-destructive probabilistic trends: A perceptual and behavioral study on video game players.

Technology in Society, 65(January), 101530.

https://doi.org/10.1016/j.techsoc.2021.101530 